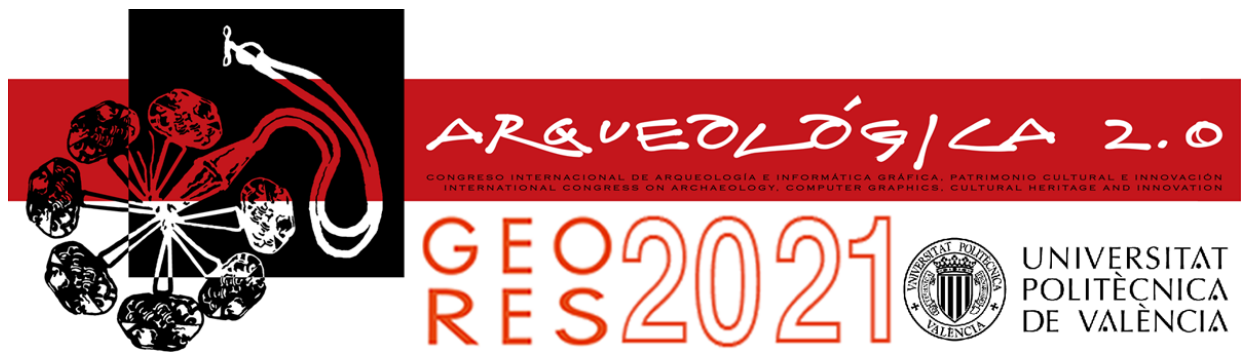

Proceedings of the joint international event $9^{\text {th }}$ ARQUEOLÓGICA

$2.0 \& 3^{\text {rd }}$ GEORES

Valencia (Spain).

26-28 April 2021

\title{
ENHANCING AND MANAGING DATA AND DIGITAL COMPETENCIES FOR ARCHITECTURE TEACHING AND TRAINING IN THE FIELD OF PROTECTION OF HERITAGE
}

\author{
Nora Lombardini ${ }^{a}$, Cristiana Achille ${ }^{b}$, Cinzia Tommasi ${ }^{b}$, Elena Fioretto ${ }^{a,{ }^{*}}$ \\ ${ }^{a}$ Department of Architecture, Built Environment and Construction Engineering (ABC), Politecnico di Milano, Via Ponzio 31, 20133 \\ Milano, Italy. nora.lombardini@polimi.it; elena.fioretto@polimi.it \\ b 3D Survey Group, ABC Lab, Department of Architecture, Built Environment and Construction Engineering (ABC), Politecnico di Milano, \\ Via Ponzio 31, 20133 Milano, Italy. cristiana.achille@polimi.it; cinzia.tommasi@polimi.it
}

\begin{abstract}
:
Given the growing relevance, at national and international levels, of restoration and conservation interventions on existing buildings, the universities have developed degree courses with specific addresses in "Conservation of Architectural and Environmental Heritage". The students that attend this course become a graduate with specific, extensive, and updated skills in the field of knowledge, protection, conservation, reuse and enhancement of architectural and environmental heritage. The complexity of the intervention is faced through the contribution of the various disciplines that contribute to the training of the architect, at the same time they studied modern instruments and tools for collecting and managing data, from on-field survey to sharing projects and ideas. The goal is to learn to manage, in its entirety, the project and the range of possible interventions with deep conservative sensitivity, with skills ranging from maintenance to restoration and redevelopment, both in the dimension of the single building and the urban and landscape scale.
\end{abstract}

Keywords: cultural heritage, digital competences, conservation, learning, HBIM

\section{Education in the protection of heritage}

According to the Italian school of Architecture, the architects must be trained in the field of conservation of architectural heritage (Di Stefano, 1975). The reason for this need is rooted in the Italian laws of 1925 under which only the architects, immediately after the master's degree, State examination and professional qualification, can work on the "monuments" of the national list. For this reason, architects must be able, right from the beginning of their work experience, to interact with the offices in charge of controlling the works on the heritage, such as the Soprintendenza Archeologia, Belle Arti e Paesaggio, the special Commissions of the Roman Catholic Church (in charge for the control of the safeguarding of the artistic and religious value of the churches) and the municipal, provincial and regional authorities of the Italian government. Nowadays, considering the adoption of the sustainable approach in the urban development, the attention is mostly devoted to the recovery of the existing urban structures and, especially, the existing buildings, in order to enhance, as the Brundtland Report/Our Common Future states (Brundtland Commission, 1987), a sustainable growth. The new attention to the existing buildings (not only architectural heritage) is strictly connected with the special economic/social Italian situation. It is imposing the needs both to improve the training on the analyses and the understanding of what is already built, pushing on the needs to use all the training and educational approaches in order to improve the ability of the future architects to grasp the existing structures, using advanced technologies. Moreover, it is useful to remember the introduction of new rules in the public procurement applications, imposing the need to use the BIM process for the submission of projects on existing structures and existing buildings (UNI 11337, 2017). The necessity of BIM in the management of existing buildings is well recognized today. What is already and not definitively solved is what kind of implementation needs the BIM procedure on the existing structures. What are the parameters useful to describe the process is one of the main questions to be solved. This research must be developed at different levels, concerning the contents and the methods to share the knowledge at local and international levels. This is both because it is necessary to improve the involvement of local communities in the participation of the management phase, and because, for the professionals, the labour market is day by day more widespread, and not only restricted within national borders. What is very urgent, furthermore, is the internationalisation of the classrooms and, consequently, the backgrounds of the students. The sharing of knowledge is the priority at several levels described and 
it is one of the aims of the educational strategy (UN 17 goals, quality education and EU roles - Bologna Process). Considering the growing importance assumed in the international framework by interventions on buildings, universities have developed degree courses with specific addresses in 'Conservation of Architectural and Environmental Heritage' (Di Biase \& Albani, 2019). These courses of study aim at training students with specific, indepth, and up-to-date skills in the field of knowledge, protection, conservation, reuse, and enhancement of architectural heritage and environment. The specific issues are faced through the contribution of the various disciplines as an addiction to the training of the architect. Particular attention is paid to the history of protection and restoration, to the methods of investigation, diagnosis and evaluation of the building, to the selection criteria between conservation and transformative approaches (Musso, 2008). The goal is to manage each phase of the project and the range of possible interventions with a deep conservation sensitivity: from maintenance to restoration, renovation, and addition, both in the size of the single building, and at the scale of urban contexts and landscape.

One of the stronger points of the conservation approach (at training and professional level) was, until quite recently, the possibility to "touch" the building. Several different boundary conditions, such as the restrictions imposed by the governments during the lockdown due by Covid-19, have shown that it is necessary to define different approaches able to decrease the necessity, for the students, to have direct access to the case of study. First of all, what it is necessary to do in order to avoid this gap, is to collect, arrange and use all the available sources and data connected with the cases of study (Achille, Lombardini \& Valentini, 2012). Starting from the point that often we have an excess of data, the management of the existing ones can represent the training starting point. The second issue is to bypass the involvement of the students, directly, in the phase of collecting data, offering them a materials' package, introduced and explained by professors, that they have to understand, manage, imputing, improve and disseminate. This approach requests the necessity to arrange the existing data by trainers and institutions. Also, for this reason, it is very urgent the optimisation of the knowledge, in order to create a database useful for its sharing. This gap in the data organisation represents the weakness in the data processing, both in the higher institution training and, also, in the control and supervision that the public administration must exercise for the cultural heritage supervision and dissemination.

\section{Competences on conservation project data and methodologies}

The Learning Conservation Practices (LCPP) are based on the study of the building (or/and the built environment) in its authentic dimension (ICOMOS, 1994).

Each object constitutes a singularity that even the use of new digital technologies and related skills are able to grasp. The determination of this singularity requires a precise study of the history of its construction phases, of construction techniques and of materials. Decays, alterations and failures are detected and analysed to proceed with the conservation project which, through the identification of the urban, social, economic characteristics of the context, requires that its use ought to be confirmed or renewed.

The project is developed considering both the structural and energy efficiency of the building.

It is therefore evident that the information necessary for the preparation of a conservation project, which involves all the most up-to-date restoration techniques, must combine digital skills and the necessary information for the building knowledge. The description of the existing building, especially the old one, is not based on standardized data. The protocols concern not the data (as happens today with the new buildings), but the procedures for detecting data (UNI 11182, 2006).

\subsection{Digital and theoretical competencies}

Today, thanks to the digital tools at disposal, it is possible to partially compensate for the inability to go to the site (Covid 19). When data have been already recorded, the students are able to do a 'digital survey' exploring point clouds and use them with images to check in a deep way the object characteristics. Data acquisition is a consolidated process, workflow and techniques are well established (Remondino, 2011; loannides, Fellner, Georgopoulos \& Hadjimitsis, 2010; Bianchi et al., 2016; Fassi, Fregonese, Ackermann, \& De Troia Fassi, 2013).

Today the main techniques available include total station and GNSS surveying, terrestrial laser scanning (TLS) and photogrammetry (close range and UAV).

The geometric survey is generally done through an integrated survey, in this way it is possible to obtain different products (point clouds, orthophoto, precise measures) and compensate for the eventual limitations of a single technique.

The combination of different techniques permits a sensible on-site time reduction, simultaneously the acquired data is multiscale and multi-functional.

The survey must be as complete and exhaustive as possible, it must return the shape and position of the elements to the selected scale, thus guaranteeing the appropriate level of resolution, as described in the international guidelines (Bryan, Blake, Bedford, Barber \& Mills, 2009; ICOMOS, 2003; Historic England, 2018, Heritage Association of South Africa, 2019). The difficulties lie not so much in the use of the survey tools, but in the subsequent data processing. The process is known as scan-to-BIM and provides progressively construction of 3D objects (as elements windows, decoration, walls, foundations, roofs, vaults, ceilings and their construction, as the core of masonry construction: brickworks, stone works that make the building). Conservation projects are based on the collection, analysis and interpretation of a significant amount of heterogeneous data to develop a good project from the structural, efficient energy and adaptive re-use point of view (Achille, Lombardini \& Tommasi, 2016).

BIM process applied to Historical building becomes HBIM (Murphy, McGovern \& Pavia, 2009; Murphy, McGovern \& Pavia, 2011), and it represents an information system at the architectural scale and makes it possible to manage semantically enriched 3D models, sustaining a study and the analysis of historical buildings. 
The increasing ability to manage and process data by the HBIM software and its progressive customization levels have, in fact, made them an interesting alternative for the collaborative management of information and projects. The three-dimensional modelling phase mainly focuses on how to parameterize complex elements and how to model structural deformations and irregularities typical of the existing architecture (Tommasi \& Achille, 2017). Until now, no BIM software has proved adequate to directly model the shapes of the existing building from data in a point cloud format. The standard object libraries do not fully satisfy the needs of the representation of the existing building, especially when the scale of the drawing shows a high level of detail. For this reason, the research explores different strategies for recognizing, modelling and managing data, from the creation of a library of parametric architectural elements (Dore, \& Murphy, 2013) to the segmentation of raw data (Teruggi, Grilli, Russo, Fassi \& Remondino, 2020). The goal is always to 'recognise' the architectural elements and the construction of the building so that it can be effectively managed by the HBIM process. The final model is the best compromise between architectural analysis (recognition of the element according to the vocabulary) and tools and software used (Fai, \& Rafeiro, 2014; Bruno \& Roncella, 2019). The students training must develop a critical capability to identify and build the model of the object, finalizing the aim of the project.

The survey with advanced tools such as laser scanner, after the processing and the elaboration of the data, represents the object as-built and the envelope as it is. The aim of the modelling phase of the object is to link to the envelope the necessary information to describe the object in relation to the conservation project's aim.

The 3D model has to collect the data required to evaluate the building for its conservation.

That is why the BIM process seems the best way to do it, the structure of the software (parametric and objectoriented) lets to connect the 3D objects to specific information obtaining in this way an 'information system of the building'.

This kind of association is not possible with other modelling techniques, even if the BIM process can present some limits when the building is an existing one (Achille, Lombardini, \& Tommasi, 2018). In fact, the nonstandard materials and the class of information required for the conservation, make it hard to match the BIM process functionalities with these kinds of needs.

The level of detail (LOD) of the 3D model should be appropriate to the survey data acquired. It is important that the building is modelled in each of its components because the information refers not to the entire building, but to the single objects. The Italian standard defines 7 LOD degrees, indicated with letters A to G. Each level refers to a specific maturity of the object (UNI 11337, 2017; Lombardini, Achille \& Valentini, 2017). This classification introduces the LOD $\mathrm{G}$, intended as a life cycle LOD. This LOD, representing the evolution of the object during its lifetime and the transformation that occurred, it is a further in-depth level (Fig. 1).

The LOD $G$ represents a novelty in the international regulatory framework. All the interventions of management, maintenance, replacement, and all the material and decay description in time have to be included in the LOD G.

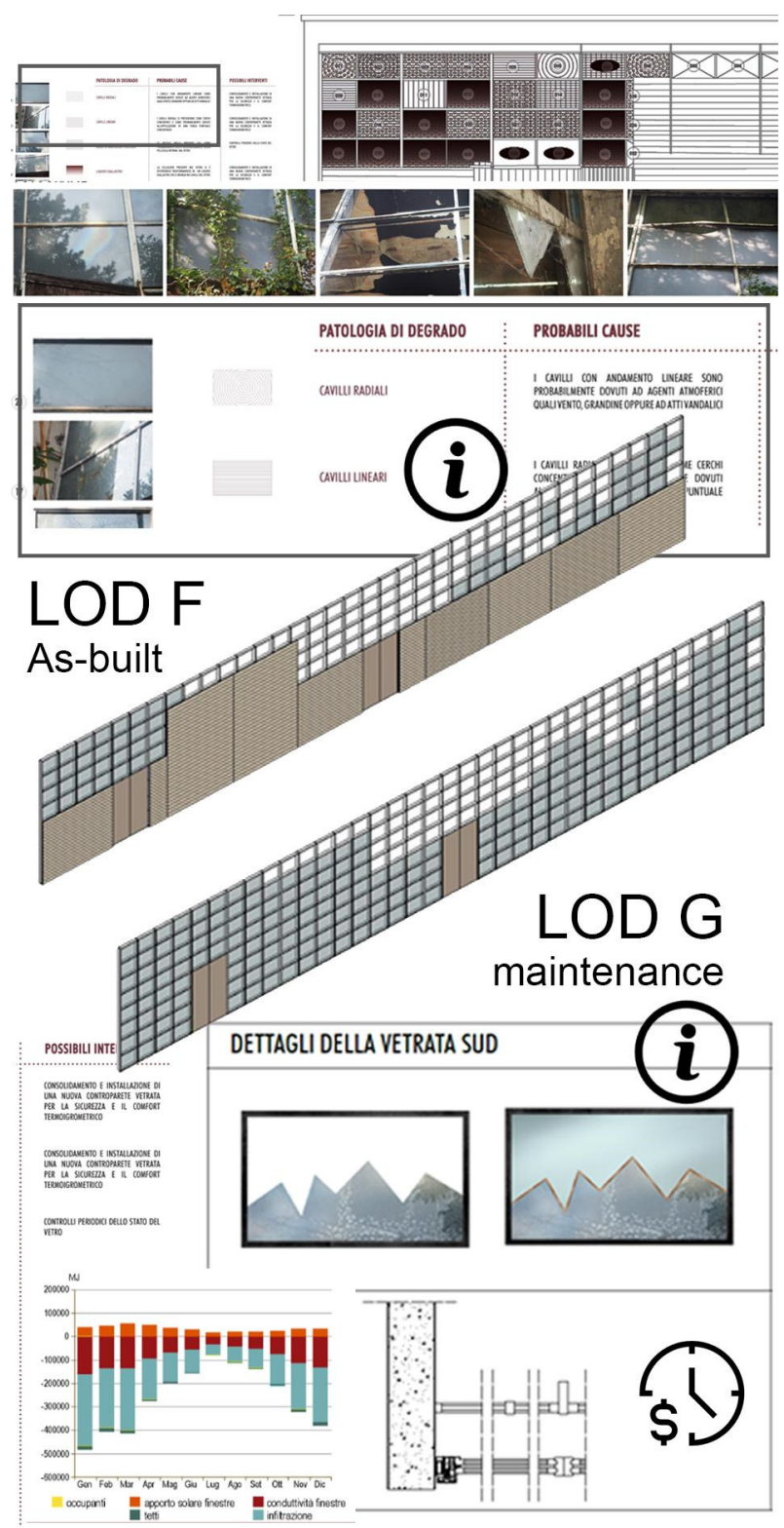

Figure 1: Differences between the LOD for Restoration according to UNI 11337:4. Top line: LOD G has to represent the as-built phase, and for this reason, it contains all the information about the existing building, such as decay and material

analysis. LOD F, instead, represents the maintenance and conservation program, showing the ordinary and extra-ordinary interventions.

The localisation in the 3D model of the analyses and the state of decay relating to materials in the HBIM platform contributes to enrich the database itself, with data that can be effectively used to design interventions (Chiabrando, Lo Turco \& Rinaudo, 2017). The issue of collecting historical qualitative data is a delicate one and is often not sufficiently evaluated. Historical semantic data (photographs, historical archives, original drawings, texts, ...) are frequently discussed in disciplinary fields other than those that directly involve the BIM and HBIM process. These data are also often presented in paper form and must be digitized before being inserted into a relational database. 
There are no guidelines or other references that indicate which and how much data should be digitized and organized through HBIM.

It is, therefore, essential that during the degree course students are 'trained' to recognize, choose, digitize, and organize the data necessary for the success of the project. Good knowledge of software tools must be accompanied by critical and data selection skills; this skill must allow evaluating when the tools already present in the software are sufficient or when it is necessary to create ad hoc databases connected to HBIM models. All necessary information must not be lost and need to be properly filed. In this way, it is possible to associate the modelled objects with both the selected info and parameters that describe the history and state of conservation of the building and the description of the interventions necessary for the restoration. The purpose for selecting the HBIM process is the potentialities that it offers to connect the 3D representation with an information database and the predisposition of managing the whole life cycle of the building, especially the maintenance, following national and international legislation (UNI 11337, 2017; EUPPD, 2014). The data inserted in the database strictly depend on the value that the architect assigns to them. Training, both theoretical ones and practical on-site, plays a fundamental role.

\subsection{HBIM conservation project}

At the end of the elaboration, each student group has at disposal the 'digital twin' (Raghunathan \& Barma, 2019; Farsi, Daneshkhah, Hosseinian-Far \& Jahankhani, 2020), with the data useful to manage the building, 3D model, and metadata about the state of art are the basis for the conservation project. In this phase, the target is to build capacity for the 'virtual design' of interventions based on the collected data. In this phase, the target is to build capacity for the 'virtual design' of interventions based on the collected data. The design process for conservation managed by BIM-based systems contemplates numerous temporal and managerial advantages. The process shares quickly the information among the actors: project proposals can be immediately analysed; errors identified, in order to choose the best solution. The careful design makes performance measurable of the intervention, the specialist contribution of all the actors involved is enhanced. The so-called 'facility management' takes advantage of the information stored in the database and uses it to evaluate the life cycle of the planned activities (Eastman, Teicholz, Sacks \& Liston, 2016). The HBIM process encourages and supports teamwork. Working in the architectural field, by its nature, requires teamwork. It is necessary to learn to work together, encouraging multidisciplinary cooperation and dynamic interchange among the students/teachers and professional people.

HBIM can be an efficient method to handle and manage a building, including costs, energy simulation, construction and production data. The scientific literature shows (Bruno \& Roncella, 2019, Dore et al., 2015; Fai, Graham, Duckworth, Wood \& Attar, 2011; Fassi, Achille, Mandelli, Rechichi \& Parri, 2015; Fregonese et al., 2016) that the use of digital models and HBIM process provides a lot of advantages: the building can be documented over time cataloguing material and decay state, it is easy to recognise the different construction phase keeping track of all intervention and support maintenance plan, all data are collected in a unique database, structural and energetic analysis is supported, BIM process support web sharing, hypothesis virtual reconstruction, and Augmented Reality. The use of HBIM-type software aims to improve the effectiveness of data management processes among stakeholders, to ensure more reasonable conservation of the existing built heritage, and to reduce the costs associated with conservation and enhancement projects (Jouan \& Hallot, 2019).

The students at the end of the training path are obliged to show the technical and digital competencies acquired during the course. The assessment is to create new and original work starting from the technical drawings and 3D models. The first step is to visualise their workflow representing it in large boards: from survey to 3D model, the HBIM potentialities (Fig. 2). From there, they can build their project enhancing the protection of the heritage through digital technologies, and its valorisation through the reuse of the spaces for social and community purposes.

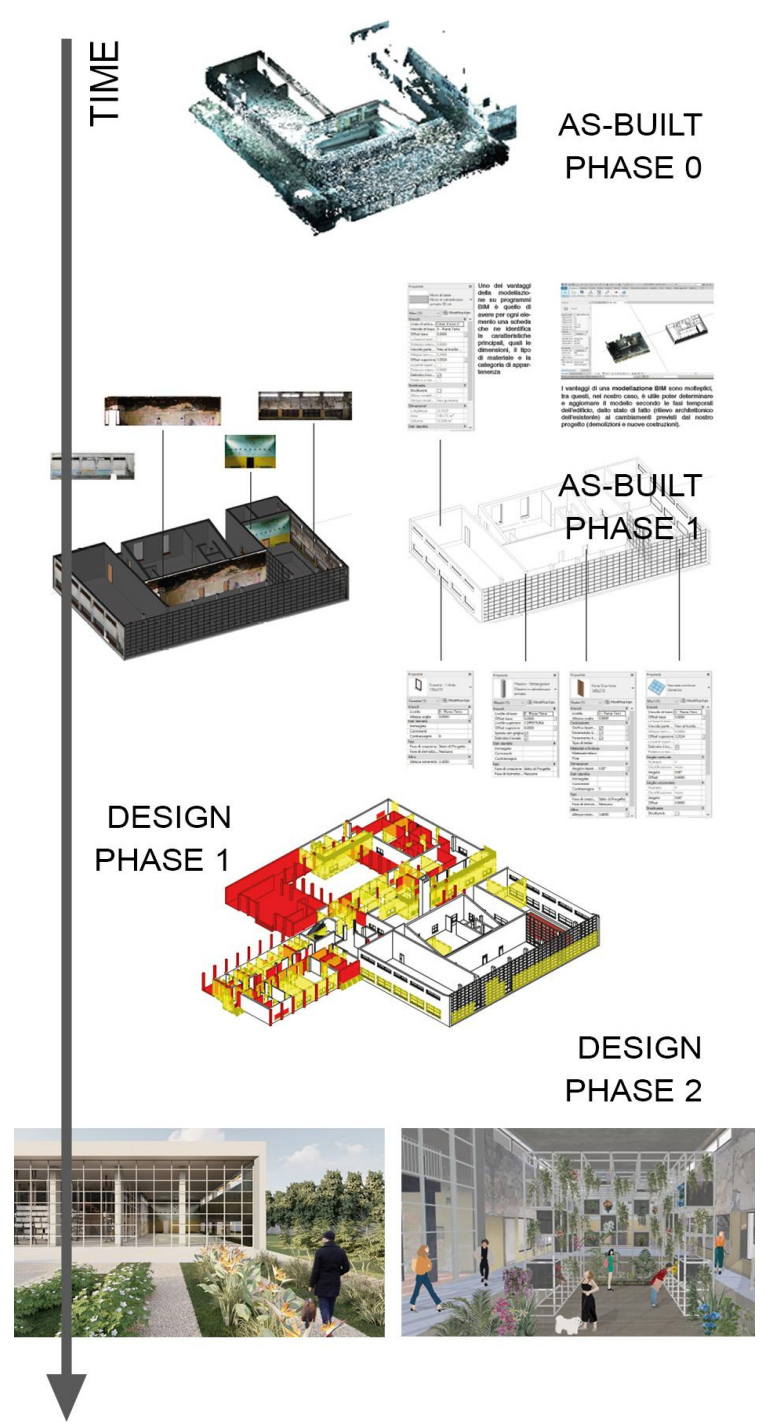

Figure 2: General The phases of the conservation process that the students have to face: from the as-built assets, point cloud and HBIM model with maintenance and restoration information, to the design assets, studying the phases of the project, and the re-use of the building. 


\subsection{Sharing data}

Sharing the project and the final product is an important step for learning how to disseminate the work between other kinds of targets, which can include nonprofessionals, or people from other fields. Today, a project accessed only by expert users is out of date and without a future as much as its effectiveness is measured in terms of social and cultural impact on society (Tommasi, Achille, Fanzini \& Fassi, 2020).

The education and learning areas give the possibility to create participation and involvement, enriching personal knowledge and awareness for the process of conservation. Its efficiency and continuity depend on the development of new research and design competencies, also through specific training paths. Today it is necessary to overpass the "traditional" idea of the training course: good technical skills are not enough anymore, but it is mandatory to combine technological expertise with the social impact of the data collected, where education is related to access and participation, conservation, and sustainability (Tommasi, Achille, Fanzini \& Fassi, 2020).

The integrated and suitable planning and management of heritage should be based on the mediation amongst institutions, businesses and universities, as well as the other cross-sectional elements connecting these three main protagonists of the valorisation project (Fanzini, Casoni, \& Bergamini, 2014):

- Conservation, concerning the growth and the diffusion of knowledge related to heritage, its features and particularities and terms of the promotion of new strategies and supply chains aimed at restoration and valorisation.

- Usage, as a lever of social and economic sustainability of conservation and precondition for the effective re-appropriation of cultural, environmental and landscape heritage.

- Development, through promoting creative activities and innovation process relying on culture to create new values and new heritage (an increase of cultural capital, development of cultural tourism, enhancement of real estate values, entrepreneurial growth in the areas of conservation and craftsmanship, etc.).

This approach helps to handle the requests also from the professional field, helping to reduce the gap between academia and work.

Moreover, the soft skills developed during this sharing phase as the project's communication and collaborative design in teams, can be spent in both real life and digital environments.

\section{Conclusion and future developments}

The digital management of information on architectural heritage is a problem not yet completely solved, as an object of architectural heritage requires an integrated representation of various types of information in order to develop appropriate conservation strategies.

The ability to use digital tools must be accompanied by a profound critical ability to analyse and manage data:
HBIM models must allow evaluating data beyond the data themselves.

The progressive transition from 2D drawings-3D modelsHBIM models is not only the transition from twodimensional representations to volumetric objects but it is a more complex operation. Conservation professionals don't need a model 'only' to navigate documents but also to perform spatial and temporal analyses and multicriteria queries in a virtual $3 D$ environment, to support design choices.

Restoration training in higher education aims to develop the framework of criteria, procedures and tools oriented towards the conservation of cultural heritage, satisfying the key theme of Responsible Research and Innovation (RRI) about "Science and Education". The demand for highly qualified people in the European Union is expected to rise significantly in the coming years. Improved science teaching could promote research as a career and provide citizens with the knowledge and skills they need to take part in discussions and decisions on research and innovation (European Union, 2016).

This approach and the goals require a multidisciplinary teaching team, able to provide different approaches and interpretative keys thanks to skills and experience in the fields of conservation, restoration and enhancement, cultural design and digital technologies and communication for cultural heritage (Lombardini, 2011).

With these assumptions as a starting point, the training path of Restoration Studio is organized into the following principal phases of investigation and experimentation (Fig. 3):

1) The first phase deals with the development of the theoretical framework and the creation of rules for data collection, information processing and knowledge management. The quali/quantitative analysis of data through innovative applications will allow for the recognition and connection of the case study assets. The result of this phase will be the development of an investigation map/model/drawings - based on a set of data and criteria and processing procedures - for identifying and describing the territories and their cultural assets suitable for enhancement.

2) The second phase proposes a set of innovative strategies, tools, educational programs, and experiences for the enhancement of case study heritage assets. The project developed on the case study allows for the application and testing of the theoretical framework and proposed model for involving various categories of stakeholders, to assess the possible interconnected impacts on the building.

3) The communication and dissemination of the outcomes of the research will not only enable knowledge sharing, but also the collection of more data and the improvement of the theoretical framework and the model.

In this training path, new technologies offer spaces for improvement for the students, especially in this time that requires the adoption of digital learning. 
These benefits, however, require a structured approach of management and use of the hardware and software tools at disposal, and the attitude to learn and test new solutions. Restoration studio in this framework can represent a "best practice" sustaining the laboratorial digitalisation (remotisation) and teaching stuff with multidisciplinary skills and competencies. But, during this time, it is necessary to think about how is it possible to make the training path more effective? How can it be more engaging when the fruition is almost $100 \%$ online?

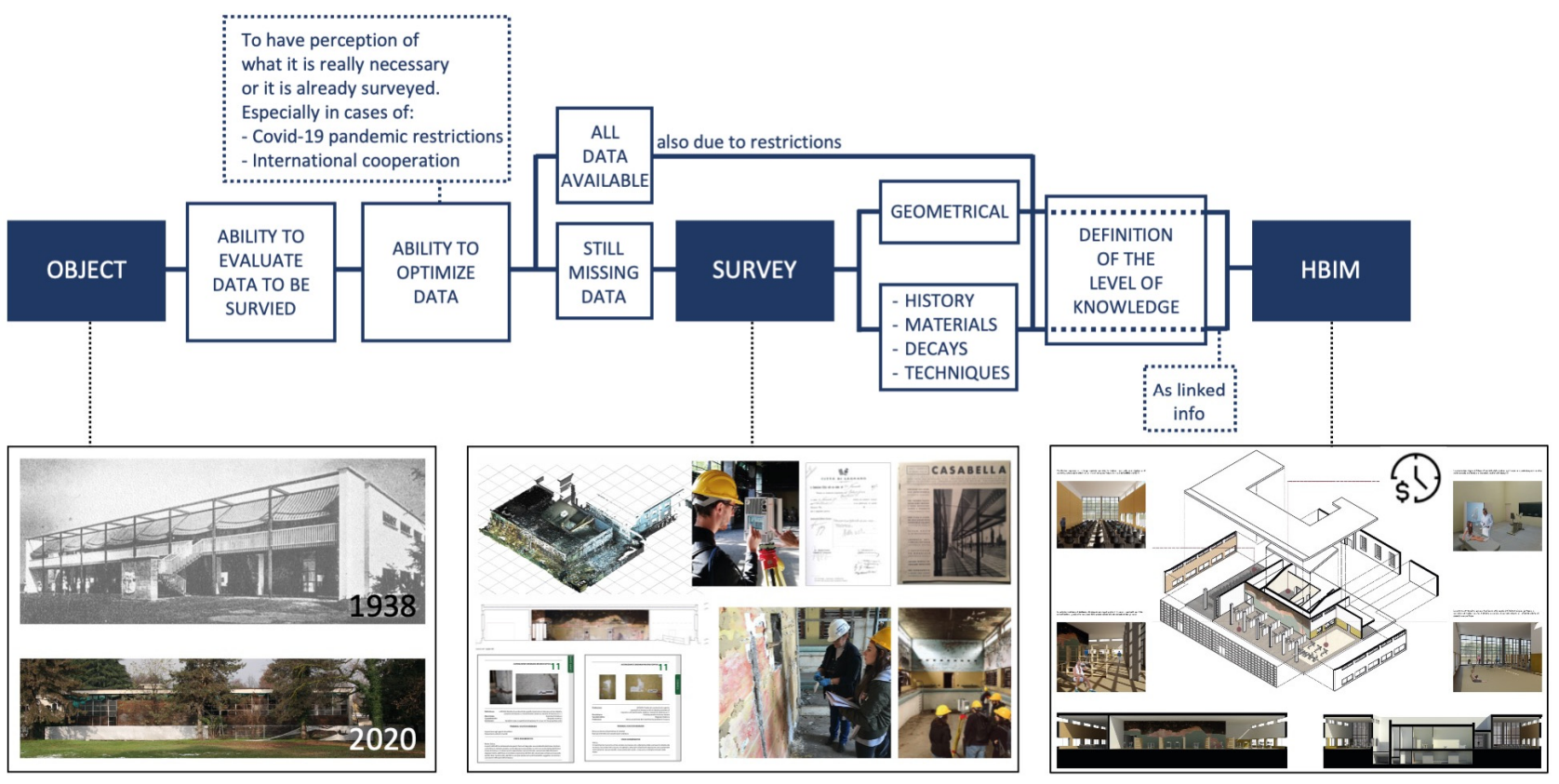

Figure 3: "Best practice" of the workflow and training path for learning about conservation processes. The path considers two different scenarios: one "linear" where there is the possibility to go on the field to perform surveys and analyses, and the second where, maybe also due to restrictions (e.g., COVID-19), there is no possibility to go on the field to collect data, and where the students receive a pack of data already acquired.

The Covid-19 pandemic accelerated the digitalisation processes already in progress and highlighted the structural, organisational, and social limits of the entire school system (Agasisti, 2020). For this reason, it is necessary to think about not a passive adaptation of the courses in the emergency time, but preventive planning of the learning path in a digital way. In this way, it will be possible to turn a critical issue into a transformation of the education projected towards the future.

\section{References}

Achille, C., Lombardini, N., \& Valentini, M. (2012). Aree archeologiche e sistemi di protezione: modelli di valutazione di compatibilità. Scienza e beni culturali XVIII, 268-279, Bressanone, Italy.

Achille, C., Lombardini, N., \& Tommasi, C. (2016). BIM and Cultural Heritage: Compatibility Tests in an Archaeological Site. International Journal of 3-D Information Modeling (IJ3DIM), 5(1), 29-44. https://doi.org/10.4018 / IJ3DIM.2016010103

Achille, C., Lombardini, N., \& Tommasi, C. (2018). BIM and Cultural Heritage: compatibility tests on existing buildings. In B. Kumar (Eds.), Contemporary Strategies and Approaches in 3-D Information Modeling (pp. 1-26). https://doi.org/10.5194/isprs-archives-XLII-2-W5-497-2017

Agasisti, T. (2020). Opportunità, limiti e paradossi della didattica a distanza. Quotidiano Politecnico 1863, 9.

Bianchi, G., Bruno, N., Dall'Asta, E., Forlani, G., Re, C., Roncella, R., Santise, M., Vernizzi, C., \& Zerbi, A. (2016). Integrated survey for architectural restoration: a methodological comparison of two case studies. The International Archives of the Photogrammetry, Remote Sensing and Spatial Information Sciences, XLI (B5). https://doi.org/10.5194/isprsarchives-XLI-B5-175-2016

Brundtland Commission (1987). Our Common Future. Oxford University Press.

Bruno, N., \& Roncella, R. (2019). HBIM for Conservation: A New Proposal for Information Modeling. Remote Sensing, 11(15), 1751. https://doi.org/10.3390/rs11151751

Bruno N., \& Roncella, R. (2019). A restoration oriented HBIM system for cultural heritage documentation: the case study of Parma cathedral. The International Archives of the Photogrammetry, Remote Sensing and Spatial Information Sciences. https://doi.org/10.5194/isprs-archives-XLII-2-171-2018

Bryan, P., Blake, B., Bedford, J., Barber, D., \& Mills, J. (2009). Metric Survey Specifications for Cultural Heritage. Andrews Ed.; English Heritage Swindon, UK. 
Chiabrando, F., LoTurco, M., \& Rinaudo, F. (2017). Modeling the decay in an HBIM starting from 3d point clouds a followed approach for cultural heritage knowledge. ISPRS - International Archives of the Photogrammetry, Remote Sensing and Spatial Information Sciences. XLII-2/W5, 605-612. https://doi.org/10.5194/isprs-archives-XLII-2-W5-605-2017

Di Biase, C. \& Albani, F. (2019). The Teaching of Restoration at the Architecture School of the Politecnico di Milano. Traditions and Perspectives. In Di Biase, C., Albani, F., The Teaching of Architectural Conservation in Europe, (pp. 17-75), Santarcangelo di Romagna (IT): Maggioli Editore.

Di Stefano, R. (1975). La formazione dei restauratori in Italia e all'estero. Restauro, 4(20), 25-28.

Dore, C. \& Murphy, M. (2013). Semi-Automatic Modelling of Building Façades with Shape Grammars using Historic Building Information Modelling. ISPRS - International Archives of the Photogrammetry, Remote Sensing and Spatial Information Sciences. XL-5/W1, 57-64. https://doi.org/10.5194/isprsarchives-XL-5-W1-57-2013

Dore, C., Murphy, M., McCarthy, S., Brechin, F., Casidy, C. \& Dirix, E. (2015). Structural simulations and conservation analysis - historic building information model (HBIM). International Archives of Photogrammetry, Remote Sensing and Spatial Information Sciences, 40(5/W4). https://doi.org/10.5194/isprsarchives-XL-5-W4-351-2015

Eastman, C., Teicholz, P., Sacks, R., \& Liston, K. (2016). BIM Handbook: A Guide to Building Information Modeling for Owners, Designers, Engineers, Contractors, and Facility Managers. New Jersey (US): John Wiley \& Sons.

EUPPD. (2014). European Union Public Procurement Directive, 2014/24.

European Union. (). RRI Tools. A practical guide to Responsible Research and Innovation. Key Lessons from RRI Tools. Retrieved November 15, 2020, from: https://rri-tools.eu/-/rri-tools-a-practical-guide-to-responsible-research-andinnovation-key-lessons-from-rri-tools-\#

Fai, S., Graham, K., Duckworth, T., Wood, N. \& Attar, R. (2011). Building Information Modelling and heritage documentation. Proceedings XXIII International CIPA Symposium, Prague, Czech Republic.

Fai, S. \& Rafeiro, J. (2014). Establishing an Appropriate Level of Detail (LoD) for a Building Information Model (BIM) West Block, Parliament Hill, Ottawa, Canada. ISPRS Annals of Photogrammetry, Remote Sensing and Spatial Information Sciences, II-5, 123-130. https://doi.org/10.5194/isprsannals-II-5-123-2014

Fanzini, D., Casoni, G., \& Bergamini, I. (2014). Valorizzazione dei Beni Culturali \& Sviluppo Locale. Enhancement of Cultural Heritage and local development. Santarcangelo di Romagna (IT): Maggioli Editore.

Farsi, M., Daneshkhah. A., Hosseinian-Far. A. \& Jahankhani. H. (2020). Digital Twin Technologies and Smart Cities (Internet of Things). Springer International Publishing.

Fassi, F., Achille, C., Mandelli, A., Rechichi, F. \& Parri, S. (2015). A new idea of BIM system for visualization, web sharing and using huge complex 3D models for facility management. The International Archives of the Photogrammetry, Remote Sensing and Spatial Information Sciences, 40(5/W4), 359-366. https://doi.org/10.5194/isprsarchives-XL-5W4-359-2015

Fassi, F., Fregonese, L., Ackermann, S. \& De Troia, V. (2013). Comparison between laser scanning and automated 3D modelling techniques to reconstruct complex and extensive Cultural Heritage areas. ISPRS Workshop 3D-ARCH: $3 D$ virtual reconstruction and visualization of complex architectures, Trento, Italy.

Fregonese, L., Achille, C., Adami, A., Fassi, F., Spezzoni, A., \& Taffurelli, L. (2016). BIM: An integrated model for planned and preventive maintenance of architectural heritage. Digital Heritage, 77-80. Granada, Spain. https://doi.org/10.1109/DigitalHeritage.2015.7419456

Heritage Association of South Africa. (2019). Guide to conduct a heritage survey. Retrieved November 15, 2020, from: https://heritagesa.org/guide-to-conducting-a-heritage-survey/

Historic England. (2018). 3D Laser Scanning for Heritage. Advice and guidance on the use of laser scanning in architecture and archaeology. Retrieved November 15, 2020, from: https://historicengland.org.uk/images-books/publications/3dlaser-scanning-heritage/

ICOMOS. (1994). The Nara Document on Authenticity. Retrieved November 15, 2020, from: https://www.icomos.org/charters/nara-e.pdf.

ICOMOS. (2003). Icomos Charter. Principles for the analysis, conservation and structural restoration of architectural heritage. Retrieved November 15, 2020, from: https://www.icomos.org/en/about-the-centre/179-articles-enfrancais/ressources/charters-and-standards/165-icomos-charter-principles-for-the-analysis-conservation-andstructural-restoration-of-architectural-heritage

Ioannides, M., Fellner, D. Georgopoulos, \& A. Hadjimitsis, D. (2010). Digital Heritage. Third International Conference, EuroMed 2010. Lemessos, Cyprus. https://doi.org/10.1007/978-3-642-16873-4

Jouan, P., \& Hallot, P. (2019). Digital twin: a HBIM-based methodology to support preventive conservation of historic assets through heritage significance awareness. ISPRS - International Archives of the Photogrammetry, Remote Sensing and Spatial Information Sciences. XLII-2/W15, 609-615. https://doi.org/10.5194/isprs-archives-XLII-2-W15-6092019 
Lombardini, N. (2011). The necessity of knowing the different strategies of conservation for the inspiration of cultural progress. In Fioravanti, M. \& Mecca, S. (Eds.), The safeguard of cultural heritage. A challenge from the past for the Europe of tomorrow, pp. 304-305.

Lombardini N., Achille C. \& Valentini M. (2017). BIM e progetto di conservazione. In Della Torre, S. (Ed.), Reportage BHIMM - Built Heritage Information Modeling Management, pp. 1-11. Retrieved November 15, 2020, from: https://www.ingenio-web.it/Sfogliabile/ReportageBHIMM2017/index.html

Murphy, M., McGovern, E. \& Pavia, S. (2009). Historic Building Information Modelling (HBIM). Structural Survey, 27(4). https://doi.org/10.1108/02630800910985108

Murphy, M., McGovern E. \& Pavia, S. (2011). Historic Building Information Modelling - Adding Intelligence to Laser and Image Based Surveys, International Archives of the Photogrammetry, Remote Sensing and Spatial Information Sciences, 38 (5/W16). https://doi.org/10.1016/j.isprsjprs.2012.11.006

Musso, S. F. (2008). Teaching Conservation/Restoration: tendencies and emerging problems. In Musso, Stefano F., De Marco, L., Teaching Conservation/Restoration of the Architectural Heritage. Goals, Contents and Methods 1, pp. 1526, Leuven EAAE-European Ass. for Architectural Education.

Raghunathan, V., \& Barma, S. B. (2019). Digital Twin: A Complete Guide for The Complete Beginner.

“Regolamento per le professioni di ingegnere e di architetto", Art. n. 52, R.D. n.2537/1925 (1925) (Italy).

Remondino, F. (2011). Heritage recording and 3D modeling with photogrammetry and 3D scanning. Remote Sens. 3. https://doi.org/10.3390/rs3061104

Teruggi, S., Grilli, E., Russo, M., Fassi, F., \& Remondino, F. (2020). A Hierarchical Machine Learning Approach for MultiLevel and Multi-Resolution 3D Point Cloud Classification. Remote Sensing, 12(16), 2598. https://doi.org/10.3390/rs12162598

Tommasi, C. \& Achille, C. (2017). Interoperability matter: levels of data sharing, starting from a 3d information modelling. ISPRS - International Archives of the Photogrammetry, Remote Sensing and Spatial Information Sciences, XLII2/W3, 623-630. https://doi.org/10.5194/isprs-archives-XLII-2-W3-623-2017

Tommasi, C., Achille, C., Fanzini, D., \& Fassi, F. (2020). Advanced Digital Technologies for the Conservation and Valorisation of the UNESCO Sacri Monti. In: Daniotti B., Gianinetto M., Della Torre S. (Eds.) Digital Transformation of the Design, Construction and Management Processes of the Built Environment. Research for Development. Springer, Cham. https://doi.org/10.1007/978-3-030-33570-0_34

UNI 11182. (2006). Beni culturali, Materiali lapidei naturali ed artificiali Descrizione della forma di alterazione - Termini e definizioni.

UNI 11337I. (2017). Edilizia e opere di ingegneria civile - Gestione digitale dei processi informativi delle costruzioni - Parte 4: Evoluzione e sviluppo informativo di modelli, elaborati e oggetti. Retrieved November 15, 2020, from: http://store.uni.com/catalogo/index.php/uni-11337-4-2017.html 